would be stretching the imagination to apply this ingenious hypothesis to explain such an occurrence, as described above, and that it would be more natural to consider the polar cataract as one of the defects of development and nutrition, as with the other stigmata of degeneracy, for which no infection is considered necessary.

\title{
SYMPATHETIC OPHTHALMITIS DEVELOPED FORTY YEARS AFTER AN OPERATION ON THE FELLOW EYE
}

\author{
BY \\ P. Sander, M.D. \\ PORT SAID
}

J.C., Greek lady, aged 48 years, consulted me on June 22, 1928, for decrease of vision in her left eye, which she noticed two days previously, and which was increasing and was accompanied by pain in the same eye. The patient had suffered a great deal from eye troubles during her childhood. At the age of 8 years, that is to say, 40 years ago, her right eye was operated on in the French Hospital, in Alexandria. She could not tell what operation was done, or what had been the condition of the eye before the operation, but she remembered very well, that after the operation under general anaesthesia, there was severe pain in the affected eye for many weeks and she lost the sight permanently. During the whole of her life she had had sensations of heaviness and discomfort in this eye and tenderness to touch. In particular this eye had been tender during the last few months. The left eye was a source of long standing trouble in her youth. From time to time it became painful and red, and the sight failed. She consulted on many occasions many of the ophthalmic surgeons in Egypt, as well as abroad, but she was always told that it was trachomatous keratitis and was treated accordingly. They often advised excision of the right eye for aesthetic reasons, but she never agreed to it. During the last 15 years the left eye did not bother her.

Present State: R. E. Atrophic shrunken globe with gross corneal leucoma. The conjunctiva bulbi slightly injected and the eye very tender; a slight touch provoked a violent defensive retraction of the head. There was very pronounced enophthalmos with narrowing of the palpebral fissure. V. A. $=0 . \mathrm{L}$. E. Trachoma (Stage IV) Maculae corneae; ciliary injection. Corneal precipitates in form of delicate dew in the lower part of the cornea. The pupil narrow, of irregular form, did not react to light and could not be dilated with atropine drops. The fundus was not 
visible. The eye tender to pressure, but not to such a degree as the right one. Moderate photophobia and lacrymation. $\mathrm{T} .=12 \mathrm{~mm} . \mathrm{Hg} ; \mathrm{V} . \mathrm{A} .=6 / 18$; glasses did not improve it.

The Wassermann blood test a few days later proved to be negative.

The right eye was enucleated two hours after the first examination of the patient. The operation showed complete atrophy of the retrobulbar tissues. The globe was drawn back to the very apex of the orbit. Not more than $3 \mathrm{~mm}$. of the optic nerve could be excised although it was cut off close to the foramen opticum. The globe contained a bony inclusion. The postoperative treatment was one usually recommended in similar cases: every four days, intravenous injections of neosalvarsan. Daily injections of cyanide of mercury. Every three days electrargol intravenously. Locally atropine, hot fomentations, etc. For days matters seemed to be going from bad to worse. The left eye was inflamed and tender. Atropine did not dilate the pupil. V. A. fell from $6 / 18$ to $1 / 20$. But on the fifth day after the operation the symptoms began to subside. The contraction of the pupil gave way, leaving a ring of pigmented residue on the anterior capsule. The fundus became visible. The vitreous was muddy, but allowed papillitis to be seen. Slow, but steady improvement began from this day, and three months after the operation the eye was quiet, the signs of the inflammation of the uvea and optic nerve had disappeared. V. A. with - 1.0 D. sph. $=6 / 12$. From time to time I have had occasion to see the patient. Her condition has not changed since.

The onset of sympathetic ophthalmitis following an injury 40 years previously is exceptional and worthy of attention.

\section{COLOURED CRYSTALS ON THE ANTERIOR SURFACE OF THE LENSES AFFECTED BY SENILE CATARACT}

BY

P. SANDER, M.I).

PORT SAID

Mme. E. H., French, aged 62 years, consulted me on October 3 , 1928 on account of a slight blow on her left eye, which she received while nursing her grandchild. The patient, of middle stature, a sound and energetic person, mother of many grown-up children, always enjoved excellent health. Some 15 months previously she 